\title{
Smartphone Usage Posture (Sitting and Lying Down) and Musculoskeletal Symptoms among school-aged children (6-12 years old) in Nakhon Si Thammarat, Thailand
}

Jittaporn Mongkonkansai ( $\nabla_{\text {jittaporn.mo@wu.ac.th ) }}$

Walailak university

Uraiwan Madardam

Walailak University

Siriluk Veerasakul

Walailak University

\section{Research}

Keywords: Smartphone usage posture, Sitting posture, Lying down posture, Musculoskeletal symptoms, school-aged children

Posted Date: August 4th, 2020

DOI: https://doi.org/10.21203/rs.3.rs-51245/v1

License: (c) (1) This work is licensed under a Creative Commons Attribution 4.0 International License.

Read Full License 


\section{Abstract}

Background: The posture while using smartphone in school-aged children is at risk on occurring musculoskeletal symptoms. The purpose of this study is to study the postures while using a smartphone and the factors related to the abnormalities of the musculoskeletal symptoms of school-aged children.

Method: Experimental study is a method of this research. The samples were 233 school-aged children in Nakhon Si Thammarat, Thailand. Multi-stage sampling and data collection consisted questionnaire for the musculoskeletal symptoms by applying from the Nordic Musculoskeletal Questionnaire, ISO 11226: 2000 Ergonomics-Evaluation of static postures, which was a smartphone using posture evaluation form with data analysis using percentage, mean, standard deviation and Chi square.

Result: The smartphone usage posture are mostly a lying position, which is $52.4 \% .91 .5 \%$ of children has unacceptable risky smartphone usage posture. Mostly, the lying position has various organs tilted at angles, compared to the body's symmetrical axis, rather than the sitting position. The school-aged children had a prevalence of musculoskeletal symptoms of $20.2 \%$, with the lying position having a higher rate of musculoskeletal symptoms, which is $10.7 \%$. The smartphone usage posture is statistically significant correlated with the symptoms occurring in the head area. The risk of ergonomics and the musculoskeletal symptoms are statistically significant.

Conclusion: The smartphone usage posture among students is at high risk especially lying position and has a chance of a musculoskeletal symptoms, higher than the sitting position. Educating to provide knowledge about safe use of smartphones to students, parents and relevant government agencies is very important.

\section{Introduction}

Smartphone or mobile phone considered as an important thing for the lives of modern people in order to communicate conveniently and quickly. In addition, newer model of smart phones has been developed to be more versatile and more efficient, making them accessible to all age groups, especially in elementary school children. Nowadays, children can easily learn via smartphone. The children were learning how to work out the solutions for themselves rather than by being "spoon-fed" by their teacher [1]. In Thailand, here is a trend of internet usage in children aged 6-14, increasing from $35.9 \%$ in 2010 to $69.6 \%$ in 2018 . The screen times of the children internet users showed that $58.5 \%$ use internet 5-7 days per week and 40.2\% use 1-4 days per week and most children spend 1-2 hours per day [2]. Almost all children (96.6\%) used mobile devices, and most started using before age 1 . Parents gave children devices when doing house chores (70\%), to keep them calm (65\%) [3].

However, although smartphones are useful in many ways for today's communication, research has shown that the children using a smartphone has both mental health, physical effects and academics effects at the same time [4] for example, depression and anxiety, social phobia or feelings of loneliness $[5],[6],[7]$ and smartphone addiction [8]. Smartphone addiction among students is in the range of $24.8 \%-$ 
$27.8 \%$ and the trend of smartphone addiction in children increases every year [9]. Common problems found include eye problems such as dry eye, fatigue, headaches, eyestrain, presbyopia, etc [10], [11]. There are also problems with the musculoskeletal system in children who are addicted to smartphones and may develop faulty habitual posture due to constant neck flexion downward, which may place them at high risk of spine abnormalities. The international study reported flawed flexion of child neck and back while using smartphone [12], resulting in the prevalence of musculoskeletal pain was substantially high among school-adolescents [13], [14]. The study of Regina PF about the back posture in children, the result showed that children bent theirs back using smartphones in the range of 8.5-54 degrees and leaning backwards in the range of 12-24 degrees while on the screen. Both of these ranges are at risk for back and neck injuries [15]. The study of New York Spine Surgery and Rehabilitation Medicine found that flexing the neck 60 degree while using the phone is as same as applying 60-pound weight on the spine [16].

Preliminary survey found that there are many smartphones users among primary school children in Nakhon Si Thammarat province. The smartphone is used during the day, during a break time and after returning from school, in which these school-aged children use smartphone in both sitting and lying positions. Which can affect the musculoskeletal system, especially the upper limb. Other research will focus on the use of smartphones in sitting positions for adolescents and adults. However, the study of the use of smartphones in school-aged children, especially in lying positions, is still lack. Therefore, this research aims to study on the postures of school-aged children in Nakhon Si Thammarat, Thailand, while they are using a smartphone and musculoskeletal symptoms due to students' smartphones usage in a sitting and lying posture, in order to be used as information to prevent and resolve disorders and signs of musculoskeletal symptoms due to the use of smartphones in school-aged children.

\section{Material And Method}

\section{Study design}

This research was an experimental study of elementary students grade 1-6 in Nakhon Si Thammarat province, Thailand.

This research has been approved to conduct by Walailak University Ethics Committee on Human Research No. WUEC-19-061-01

\section{Study population and procedure}

The population was 308 students in elementary students grade 1-6 who have used smartphones for at least 6 months. The sample was a total of 233 elementary students grade 1-6 who have used smartphones for at least 6 months that agreed to participate in the project and obtained consent from their parents or guardians. This research was conducted between May 2019 - May 2020 by multi-stage sampling. 


\section{Research Instrument}

The instruments used in the study consisted of 4 parts as follows

1. General information questionnaire concerning gender, age, education level, medical condition, exercising, surgical history, hobbies.

2. Questionnaire about smartphone usage, consisting of owning a smartphone, duration of smartphone usage (years), screen size, usage period per day, smartphone usage frequency, parents smartphone usage rules, smartphone usage postures.

3. The musculoskeletal symptoms are evaluated by modified Nordic Musculoskeletal Questionnaire [17] and body discomfort map, which divides the organs into 4 parts, consisting of the head, trunk, shoulders and upper arms and lower arms. The assessment conducted by students coloring in the affected area of the musculoskeletal symptoms. The frequency of symptoms within the past 3 months is divided into 5 levels: never, once a month, once a week, more than 1 time per week and frequently in a week. The criterion that gives a positive result on the musculoskeletal symptoms are students with symptoms ranging from more than 1 time per week, which is based on a survey about the health behavior of children of the World Health Organization [17].

4. Smartphone usage postures questionnaire by using Goniometer as a tool for measuring the movement angle of 4 organs, consisting of the head / neck, trunk, upper arm and lower arm of the students while using the smartphone in various gestures, which are sitting and lying and compare with the reference criteria from ISO 11226: 2000 Ergonomics-Evaluation of static postures [18]. This reference criterion has two levels of interpretations for each organ, which are acceptable and unacceptable. Researcher prepares a place or simulation device be suitable for the use of smart phones in students' daily life, consisting of chairs, sofas, mats, pillows, etc. While students demonstrate gestures using a smartphone, the researcher will assess the risk by taking photos and recording video for 5 minutes. For grade 1-2 elementary students or those who are not yet fluent in reading or do not understand the questions, the researcher interviewed them and adjusted the questions to be easier to understand by using the pictures and some additional information might be asked from the parents.

The questionnaire has tool quality testing with a conformance index between Index of Item - Objective Congruence (IOC) equal to 0.9 .

\section{Data Analysis}

This study describes general information using descriptive statistical data on the use of smartphones, ergonomic risk and the prevalence of the musculoskeletal symptoms, consisting of frequency, percentage, mean, standard deviation, maximum, minimum. For inferential statistics, this research uses chi-square at $95 \%$ of confidence levels to describe relationships among variables and use SPSS version 21 program for data analysis. 


\section{Results}

\section{General Information}

Most of the respondents were female (64.8\%) with an average age of $9.95 \pm 1.659$ years, most had no underlying diseases $(90.1 \%)$, exercising $(87.1 \%)$, never having surgery in the past $(93.1 \%)$, having a hobby $(98.1 \%)$, most of them owning a smartphone (78.1\%). The sample group of smartphone users has an average usage duration of $2.3 \pm 1.458$ years, the average screen size of the smartphone was $5.5 \pm 0.890$ inches, the period that most samples used smartphone was less than 30 minutes (48.5\%) and average usage throughout the day was $138.39 \pm 103.451$ minutes per day. Most of the parents have rules about using smart phones with students $(76.4 \%)$, the posture that school-aged children used while using a smartphone the most is a lying position (52.4\%) as in Table 1.

Table 1. Descriptive data $(n=233)$ 


\begin{tabular}{|c|c|c|}
\hline General Information & Sample & Percentage \\
\hline \multicolumn{3}{|l|}{ Gender } \\
\hline Male & 82 & 35.2 \\
\hline Female & 151 & 64.8 \\
\hline \multicolumn{3}{|l|}{ Age } \\
\hline Equal to or less than 7 years old & 23 & 9.9 \\
\hline 8 years old & 27 & 11.6 \\
\hline 9 years old & 36 & 15.5 \\
\hline 10 years old & 49 & 21.0 \\
\hline 11 years old & 44 & 18.9 \\
\hline 12 years old & 54 & 23.2 \\
\hline \multicolumn{3}{|c|}{$\pm \mathrm{SD}=9.95 \pm 1.659$ years, $\mathrm{Max}=12$ years, Min $=16$ years } \\
\hline \multicolumn{3}{|l|}{ Education level } \\
\hline Grade 1 Elementary Students & 17 & 7.3 \\
\hline Grade 2 Elementary Students & 28 & 12.0 \\
\hline Grade 3 Elementary Students & 30 & 12.9 \\
\hline Grade 4 Elementary Students & 56 & 24.0 \\
\hline Grade 5 Elementary Students & 38 & 16.3 \\
\hline Grade 6 Elementary Students & 64 & 27.5 \\
\hline \multicolumn{3}{|l|}{ Medical condition } \\
\hline Have & 214 & 91.8 \\
\hline Do not have & 19 & 8.2 \\
\hline \multicolumn{3}{|l|}{ Exercising } \\
\hline Do not exercise & 28 & 10.0 \\
\hline Exercise & 205 & 90.0 \\
\hline$-\quad<30$ Minutes & 125 & 61.0 \\
\hline - $\quad$ More than 30 minutes & 80 & 39.0 \\
\hline \multicolumn{3}{|l|}{ Surgical history } \\
\hline Never undergone surgery & 224 & 96.1 \\
\hline
\end{tabular}




\begin{tabular}{|c|c|c|}
\hline General Information & Sample & Percentage \\
\hline Had undergone surgery & 9 & 3.9 \\
\hline \multicolumn{3}{|l|}{ Hobby } \\
\hline Do not have & 2 & 0.9 \\
\hline Have & 221 & 98.1 \\
\hline - $\quad$ Planting & 107 & 50.0 \\
\hline - Watching TV & 92 & 39.5 \\
\hline - $\quad$ Reading & 73 & 31.3 \\
\hline - $\quad$ Others & 72 & 30.9 \\
\hline \multicolumn{3}{|l|}{ Smartphone owning } \\
\hline Yes & 51 & 21.9 \\
\hline No & 182 & 78.1 \\
\hline \multicolumn{3}{|c|}{ Smartphone usage duration } \\
\hline$\leq 1$ year & 87 & 37.3 \\
\hline $2-5$ years & 139 & 59.7 \\
\hline$>5$ years & 5 & 3.0 \\
\hline \multicolumn{3}{|c|}{$\pm \mathrm{SD}=2.3 \pm 1.458$ years, Max $=8$ years, Min $=9$ months } \\
\hline \multicolumn{3}{|l|}{ Smartphone screen size } \\
\hline$<6$ inches & 135 & 57.9 \\
\hline Bigger than 6 inches & 98 & 42.1 \\
\hline \multicolumn{3}{|c|}{ $\pm S D=5.5 \pm 0.890$ inches, Max $=8$ inches, Min $=3$ inches } \\
\hline \multicolumn{3}{|l|}{ Usage periods (Per session) } \\
\hline$\leq 30$ minutes & 111 & 47.6 \\
\hline $31-60$ minutes & 110 & 47.2 \\
\hline$>60$ minutes & 12 & 5.2 \\
\hline \multicolumn{3}{|c|}{$\pm \mathrm{SD}=41.45 \pm 20.403$ minutes, $\mathrm{Max}=120$ minutes, $\mathrm{Min}=10$ minutes } \\
\hline \multicolumn{3}{|c|}{ Smartphone usage frequency (minutes per day) } \\
\hline$\leq 60$ minutes & 59 & 25.3 \\
\hline 61-180 minutes & 129 & 55.4 \\
\hline
\end{tabular}




\begin{tabular}{|lll|}
\hline General Information & Sample & Percentage \\
\hline$>181$ minutes & 45 & 19.3 \\
$\pm \mathrm{SD}=140.36 \pm 101.6173$ minutes/day, Min=15, Max=600 & minutes/day & \\
\hline Parents' smartphone usage rules & & \\
\hline Do not have & 55 & 23.6 \\
\hline have & 178 & 76.4 \\
\hline Smartphone usage postures & & \\
\hline Sitting & 111 & 47.6 \\
\hline Lying & 122 & 52.4 \\
\hline
\end{tabular}

\section{Ergonomic risk}

An ergonomic risk assessment found that $91.9 \%$ of the students using smartphone have unacceptable postures and the postures do not correlate with ergonomic risk as details in Table 2.

Table 2. Ergonomic risk assessment $(n=233)$

\begin{tabular}{|llll|}
\hline \multirow{2}{*}{ Posture } & \multicolumn{2}{l|}{ Ergonomics risk (Percent) } & \\
\cline { 2 - 4 } & Acceptable & Unacceptable & p-value \\
\hline - $\quad$ Sitting position & $106(45.5)$ & $5(2.1)$ & \\
\hline - $\quad$ Lying position & $108(46.4)$ & $14(6.0)$ & 0.052 \\
\hline Total & $214(91.9)$ & $9(8.1)$ & \\
\hline
\end{tabular}

When examining the smartphone usage posture with various organs, it is found that the organs are mostly angled in the lying position by comparing with the body's symmetrical axis rather than the sitting position. Beginning with the head, most students (24\%) bent their head over 25 degrees while they are in lying position. However, 72 percent did not have full head support in both sitting and lying position. As for the trunk part, students leaned their bodies forward for more than 20 degrees and most of them occurred in the lying posture for $19.3 \%$, and $44.1 \%$ had no full support. On upper and lower arm, students' posture bent their upper arms less than 20-degree angle for $66.9 \%$ and bend more than 20 degrees in both sitting and lying position on lower arm. Furthermore, smartphone usage postures were significantly correlated to trunk angle and head angle at the statistical level at $p<0.001$ as the details in the Table 3. 
Table 3. Smartphone usage posture and body angles $(n=233)$ 


\begin{tabular}{|c|c|c|c|}
\hline Body angles & Sitting Position n(\%) & Lying Position n(\%) & \\
\hline \multicolumn{4}{|l|}{ Head } \\
\hline Less than 25 degrees & $60(25.8)$ & $66(28.3)$ & $0.000 * \star$ \\
\hline 25 degrees and above & $51(21.9)$ & $56(24.0)$ & \\
\hline - Full support & $0(0.0)$ & $30(28.0)$ & \\
\hline - Without full support & $51(47.7)$ & $26(24.3)$ & \\
\hline \multicolumn{4}{|c|}{ $\pm S D=17.78^{\square} \pm 13.869^{\square}, \operatorname{Max}=60^{\square}, \operatorname{Min}=0^{\square}$} \\
\hline \multicolumn{4}{|l|}{ Trunk } \\
\hline Less than 20 degrees & $72(30.9)$ & $77(33.0)$ & $0.000 * \star$ \\
\hline 20 degrees and above & $39(16.8)$ & 45(19.3) & \\
\hline - Full support & $17(20.2)$ & $30(35.7)$ & \\
\hline - Without full support & $22(26.2)$ & 15(17.9) & \\
\hline \multicolumn{4}{|c|}{ $\pm S D=10.46^{\square} \pm 11.585^{\square}, \operatorname{Max}=50^{\square}, \operatorname{Min}=-40^{\square}$} \\
\hline \multicolumn{4}{|l|}{ Upper arm } \\
\hline Less than 20 degrees & 77(33.0) & 79(33.9) & 0.454 \\
\hline 20 degrees and above & $34(14.6)$ & $43(18.5)$ & \\
\hline \multicolumn{4}{|c|}{$\pm \mathrm{SD}=20.89^{\square} \pm 28.236^{\square}, \mathrm{Max}=150^{\square}, \mathrm{Min}=-30^{\square}$} \\
\hline \multicolumn{4}{|l|}{ Lower arm } \\
\hline Less than 20 degrees & $6(2.6)$ & $15(6.4)$ & 0.067 \\
\hline 20 degrees and above & $105(45.1)$ & $107(45.9)$ & \\
\hline \multicolumn{4}{|c|}{ $\pm S D=62.84^{\square} \pm 29.565^{\square}, \operatorname{Max}=160^{\square}$, Min $=-5^{\square}$} \\
\hline \multicolumn{4}{|l|}{ Head } \\
\hline Less than 25 degrees & $60(25.8)$ & $66(28.3)$ & $0.000^{* *}$ \\
\hline 25 degrees and above & $51(21.9)$ & $56(24.0)$ & \\
\hline - Full support & $0(0.0)$ & $30(28.0)$ & \\
\hline - Without full support & $51(47.7)$ & $26(24.3)$ & \\
\hline \multicolumn{4}{|c|}{ $\pm S D=17.78^{\square} \pm 13.869^{\square}, \operatorname{Max}=60^{\square}, \operatorname{Min}=0^{\square}$} \\
\hline Trunk & & & \\
\hline
\end{tabular}




\begin{tabular}{|lcrr|}
\hline Less than 20 degrees & $72(30.9)$ & $77(33.0)$ & $0.000^{* *}$ \\
\hline 20 degrees and above & $39(16.8)$ & $45(19.3)$ & \\
\hline - Full support & $17(20.2)$ & $30(35.7)$ & \\
\hline - Without full support & $22(26.2)$ & $15(17.9)$ & \\
\hline \pm SD $=10.46^{\square} \pm 11.585^{\square}$, Max $=50^{\square}$, Min $=-40^{\square}$ & & \\
\hline Upper arm & & \\
\hline Less than 20 degrees & $77(33.0)$ & $79(33.9)$ & 0.454 \\
\hline 20 degrees and above & $34(14.6)$ & $43(18.5)$ & \\
\hline \pm SD $=20.89^{\square} \pm 28.236^{\square}$, Max $=150^{\square}$, Min $=-30^{\square}$ & & \\
\hline Lower arm & & $15(6.4)$ & \\
\hline Less than 20 degrees & $6(2.6)$ & $107(45.9)$ & \\
\hline 20 degrees and above & $105(45.1)$ & \\
\hline \pm SD $=62.84^{\square} \pm 29.565^{\square}$, Max $=160^{\square}$, Min $=-5^{\square}$ & \\
\hline
\end{tabular}

\section{The prevalence of musculoskeletal symptoms}

School-aged children had $20.2 \%$ of the prevalence of musculoskeletal symptoms. The smartphone usage posture has no correlation with the prevalence of musculoskeletal symptoms as the details in Table 4.

Table 4. The prevalence of musculoskeletal symptoms $(n=233)$

\begin{tabular}{|llll|}
\hline \multirow{2}{*}{ Posture } & \multicolumn{2}{l}{ Student with musculoskeletal symptoms (Percent) } & p-value \\
\cline { 2 - 3 } & Have symptoms & No symptoms & \\
\hline - Sitting Posture & $22(9.5)$ & $89(38.2)$ & 1.000 \\
\hline - Lying Posture & $25(10.7)$ & $97(41.6)$ & \\
\hline Total & $47(20.2)$ & $186(79.8)$ & \\
\hline
\end{tabular}

When considering the symptom level, most students do not have musculoskeletal symptoms and when inspecting parts of the body, it was found that the highest rate of symptoms occurred at the head part of 
23 students (9.9\%), which is about more than once a week. Smartphone usage posture were significantly correlated to head symptoms at the statistical level at $p<0.05$ as the details shown in the Table 5

Table 5. Symptom Levels of various parts of the body $(n=233)$

\begin{tabular}{|lllll|}
\hline Symptom Levels & Head & Trunk & Upper arm & Lower arm \\
\hline No Symptoms & $151(64.8)$ & $196(84.1)$ & $208(89.3)$ & $204(87.6)$ \\
\hline Once a month & $36(15.4)$ & $16(6.7)$ & $10(4.3)$ & $11(4.7)$ \\
\hline Once a week & $23(9.9)$ & $15(6.4)$ & $9(3.9)$ & $12(5.1)$ \\
\hline More than once a week & $19(8.2)$ & $5(2.1)$ & $4(1.7)$ & $5(2.1)$ \\
\hline Often in a week & $4(1.7)$ & $1(0.7)$ & $2(0.8)$ & $1(0.5)$ \\
\hline Total & $\mathbf{2 3 3}$ & $\mathbf{2 3 3}$ & $\mathbf{2 3 3}$ & $\mathbf{2 3 3}$ \\
\hline Correlation with smartphone usage posture & $0.048^{\star}$ & 0.292 & 0.449 & 0.313 \\
\hline
\end{tabular}

${ }^{*} p<0.05$

Ergonomic risk correlated with musculoskeletal symptoms significantly at the statistical level at $p<0.031$ as the details shown in the Table 6

Table 6. Relevance between ergonomic risk and the musculoskeletal symptoms.

\begin{tabular}{|llll|}
\hline \multirow{2}{*}{ Ergonomics Risk } & \multicolumn{2}{l|}{ Student with musculoskeletal disorders (Percent) } & p-value \\
\cline { 2 - 3 } & Have symptoms & No symptoms & \\
\hline - Accepted & $8(3.4)$ & $11(4.7)$ & \\
\hline - Unaccepted & $39(16.7)$ & $175(75.1)$ & $0.031^{*}$ \\
\hline Total & $47(20.2)$ & $186(79.8)$ & \\
\hline
\end{tabular}

\section{Discussion}

\section{Smartphone usage postures of the students}

Most of the smartphone usage postures are in lying position with $91.5 \%$ ergonomics risk. Smartphone usage posture has a tendency to be associated with ergonomic risk. A study by Eardley et al. found that the lying posture had the most physical movement while using a smartphone, followed by sitting posture, which created a lot of movement, impact an increased risk of ergonomics [19]. From the interviews with the students, it was found that using smartphone in a lying posture would be more comfortable than 
sitting and was able to use for longer. According to the study, the researchers found that using smartphone in the lying posture demonstrated the average time used approximately 10 minutes longer than the sitting posture (average duration of lying posture $=144.92$ minutes $/$ day, average duration of sitting posture $=135.35$ minutes $/$ day). Analyzing various parts of the body, the smartphone usage posture and head/neck and trunk's angles are interrelated with statistical significance. The study indicates that the angles of head, trunk, upper arm and lower arm while in the lying posture, are higher than the sitting posture. The average head and body bending were 17.78 and 10.46 degrees, which is consistent with the research of Pope, which found that the average body angle when using a smartphone is 25.58 degrees and the maximum back flexion/extension was 50 degrees [15]. Examining by the head angle, it is found that nearly half of all students stooped their heads in a sitting and lying position, and the important point is that using a smartphone in a sitting position does not have a full head support, which is at risk for the musculoskeletal system. The weight that is pressed on the head bones increases with neck flexion. A full-grown head weighs $5 \mathrm{~kg}$ in the neutral position. As the head bends forward, the weight seen by the neck increases to $18 \mathrm{~kg}$ at $30^{\circ}$ and $27 \mathrm{~kg}$ at $60^{\circ}$ [16]. However, even though the average angles of both head and trunk are in an acceptable range, smartphone usage in students exceedingly takes up to 40 minutes at a time and more than 2 hours per day, which indicated risk of musculoskeletal symptoms. Shan et al. found that students' usage of smartphone more than 2 hours / day of students correlated with the prevalence of lower back pain and neck and shoulder pain [20]. From upper arm angle, it is also found one of the parts that is in an acceptable level was upper arm. However, school-aged children who are using a smartphone lying down with the back to the floor, need to have their shoulders lifted up and abducted to be able to focus on the smartphone screen more clearly. Likewise, the angle of the lower arm, which the arms and elbows have to be lifted when using the smartphone in a lying posture. The wrists will twist towards the body to see the screen clearer. In the study, the average angle of the lower arm was equal to 63 degrees and the maximum is at 160 degrees, which is considered an unacceptable ergonomic risk. This is consistent with the study of Eardley et al who found that using smartphone while lying down with the back to the floor caused the upper arm and wrist move extremely [19].

\section{The prevalence of the musculoskeletal symptoms}

The students had the prevalence of musculoskeletal symptoms equal to $51.5 \%$. Smartphone usage postures were irrelevant to the prevalence of musculoskeletal symptoms, which is in accord with the research of Palmer et al., he cited that there were $88 \%$ of discomfort when using mobile phone causing head / neck, back and shoulder symptoms without a trace of relation of smartphone usage and the discomfort of the body [21]. In addition, the study of [12] revealed the prevalence of head/neck (100\%), trunk $(61 \%)$, shoulders (69\%) and arms symptoms (13\%) while using smartphone respectively. When examined the various parts of the body, revealed that the students had head/neck symptoms as a highest rate and the smartphone usage postures were significantly correlated to head/neck symptoms at the statistical level at $p<0.05$. This is consistent with the research of Hadidi et al., which found that students using smartphones have a high level (24\%) of head / neck symptoms [22]. However, half of the students 
bent down their head over 25 degrees and do not have full support while using smartphone, which means that the more time students spend on smartphones, the greater risk they have for the head symptom and other part of the body also. As well as the study of Yang, et al. and Areeudomwong et al. found that nearly half of the participants' experienced neck and shoulder discomfort and fatigue while texting on a touchscreen smartphone. Students who spend more than 3 hours per day on smartphones are more at risk of upper back pain than students who spend less than 1 hour per day $(O R)=4.23, p<0.05$. The stepwise regression results indicated that the number of body parts with discomfort $(F=6.009, p<0.05)$ increased with hours spent using ancillary smartphone functions [23],[24].

In addition, if parents do not have disciplines or rules regarding the use of smartphones in students, it will have a detrimental effect on student health [25].The World Health Organization has ranked neck pain and other musculoskeletal diseases as the fourth and tenth health problems, respectively [26], Moreover, the elevated number of smartphone usage for communication may result in long-term neck pain due to prolonged periods of neck flexion [27], [28].

\section{Conclusion}

Most students lay down using their smartphones. The head, trunk, upper arm, and lower arm in the lying posture are tilted at angles more than the sitting posture, which has a high risk of ergonomics. In addition, symptoms of the trunk, upper arm and lower arm are found, especially the head/neck symptoms. The students verge to use the smartphones continuously increasingly[9]. Therefore, the protection of the health of students is important. Students, parents, school administrators and all relevant government agencies need to earnestly pay attention to the problem of student's smartphone usage in order to prevent the musculoskeletal symptoms in their span of ages.

\section{Suggestions for students and parents}

1. Avoid using the phone in the lying position.

2. Parents should have rules at home for using a smartphone, by limiting the using time of students to 20 minutes per time. After that, there should be physical exercises and eyesight.

3. School-aged children's smartphones should not be too small and should have at least 5 inches for a screen size.

4. School-aged children who are using smartphones should use a chair or sofa with the head, neck, body, and shoulders support.

5. School-aged children and parents should be provided with knowledge about the correct postures in using a smartphone.

\section{Declarations}

\section{Ethics approval and consent to participate}


This research has been approved to conduct by Walailak University Ethics Committee on Human Research No. WUEC-19-061-01

\section{Consent for publication}

All presentations of case reports have consent for publication.

\section{Availability of data and materials}

Data and material can available

\section{Competing interests}

No potential competing interest was reported by the authors

\section{Funding}

Walailak university

\section{Authors' contributions}

Mongkonkansai J. completed the data analysis and developed the manuscript, Madardam U. and Veerasakul S. analyzed and interpreted the data and final prove.

\section{Conflicts of interest}

There are no conflicts of interest.

\section{Acknowledgements}

The study was partially supported by Walailak University, Thailand.

The study team would like to thank all the participants involved in this study.

\section{References}

[1] Camilleri, M.A. , Camilleri, A.C. The Use of Mobile Learning Technologies in Primary Education. Hershey (USA): IGI Global.2020.15 p. 
[2] National Statistical Office, 2018. The 2018 household survey on use of information and communication technology (quarter 1) [Internet]. http://www.nso.go.th/sites/2014/DocLib13/2561/ict61CompleteReport-Q1.pdf?fbclid=IwAR0vNIE5c5dvJPqZDDrpkPqBz-wSvDiHOY4zGMLnRiftRlu6SUTFtH48yQ. Accessed 26June 2020 .

[3] Hilda, K., Kabali, Matilde, M., Irigoyen, Rosemary, Nunez-Davis, Jennifer, G., Budacki, Sweta, H. Mohanty, Kristin, P., Leister and Robert L.Exposure and Use of Mobile Media Devices by Young Children. Pediatrics 2015; 136 (6): 1044-1050; doi.org/10.1542/peds.2015-2151.

[4] Shoukat, S. Cell phone addiction and psychological and physiological health in adolescents. EXCLI 2019; 18: 47-50.

[5] Elhai JD, Dvorak RD, Levine JC, Hall BJ. Problematic smartphone use: A conceptual overview and systematic review of relations with anxiety and depression psychopathology. J Affect Disord 2017; 207:251-9.

[6] Panova, T, Lleras, A. Avoidance or boredom: Negative mental health outcomes associated with use of information and communication technologies depend on users' motivations. Comput Human Behav 2016; 58: 249-58.

[7] Enez, Darcin, A., Kose, S., Noyan, C. O., Nurmedov, S., Yılmaz, O., \& Dilbaz, N. Smartphone addiction and its relationship with social anxiety and loneliness. Behav Inform Tech 2016; 35(7): 520-525; doi: 10.1080/0144929x.2016.1158319.

[8] Arefin, Md. Shamsul and Islam, Md. and Mustafi, Mohitul and Afrin, Sharmina and Islam, Nazrul. Impact of Smartphone Addiction on Academic Performance of Business Students: A Case Study [Internet]. Indepen J Manag Prod 2017; 8(3): pp. 21. https://ssrn.com/abstract=3035776.

[9] Jeong, HS, Lee YS. Smartphone addiction and empathy among nursing students. Adv Sci Technol Lett 2015; 88: 224-8.

[10] Bababekova, Y., Rosenfield, M., Hue, J.E. and Huang, R.R.Font size and viewing distance of hand held smart phones. Optom Vis Sci 2011; 88(7): 795-797. doi:10.1097/OPX.0b013e3182198792.

[11] Balik, H.H., Turgut-Balik, D., Balikci, K. and Ozcan, I.C., 2005. Some symptoms and ocular sensations experienced by long term users of mobile phone. Pathol Biol (Paris) 2005; 53(2): 88-89; doi: 10.1016/j.patbio.2004.03.012.

[12] Fares, J., Fares, M. Y., \& Fares, Y. Musculoskeletal neck pain in children and adolescents: Risk factors and complications. Surg Neurol Int 2017; 8: 72;doi.org/10.4103/sni.sni_445_16.

[13] Ben Ayed, H., Yaich, S., Trigui, M., Ben Hmida, M., Ben Jemaa, M., Ammar, A., Jedidi, J., Karray, R., Feki, H., Mejdoub, Y., Kassis, M., \& Damak, J. Prevalence, Risk Factors and Outcomes of Neck, Shoulders and Low-Back Pain in Secondary-School Children. J Res Health Sci. 2019; 19(1):e00440. 
[14] El-Metwally, A., Salminen, J., Auvinen, A., Macfarlane, G., \& Mikkelsson, M., 2007. Risk factors for development of non-specific musculoskeletal pain in preteens and early adolescents: A prospective 1-year follow-up study. BMC musculoskeletal disorders 2007; 8(46);doi: 10.1186/1471-2474-8-46.

[15] Pope-Ford R., 2019. Back Flexion and Extension: The Effects of Static Posture on Children Using Mobile Devices. In: Arezes P. (eds) Advances in Safety Management and Human Factors. AHFE 2018. Advances in Intelligent Systems and Computing, vol 791. Springer, Cham; doi.org/10.1007/978-3-31994589-7_33.

[16] Hansraj KK.Assessment of stresses in the cervical spine caused by posture and position of the head. Surg Technol Int 2014; 25:277-279.

[17] Dickinson, C., Campion, K., Foster, A., Newman, S., O'rourke, A., \& Thomas, P. Questionnaire development: An examination of the nordic musculoskeletal questionnaire. Appl Ergon 1992; 23: 197201.

[18] ISO 11223 Ergonomics. Evaluation of static working postures. International Organization for Standardization, 2001: 1-20.

[19] Eardley, R., Roudaut, A.,Gill, J., Stephen JT. Investigating How Smartphone Movement is Affected by Body Posture. Publication:CHI '18: Proceedings of the $2018 \mathrm{CHI}$ Conference on Human Factors in Computing Systems April 2018 Paper No.: 202 Pages 1-8.; doi.org/10.1145/3173574.3173776.

[20] Shan, Z., Deng, G., Li, J., Li, Y., Zhang, Y., \& Zhao, Q. Correlational analysis of neck/shoulder pain and low back pain with the use of digital products, physical activity and psychological status among adolescents in Shanghai. PloS one 2013; 8(10), e78109. ; doi.org/10.1371/journal.pone.0078109.

[21] Palmer, K., Ciccarelli, M., Falkmer, T., \& Parsons, R.Associations between exposure to information and communication technology (ICT) and reported discomfort among adolescents. Work 2019; 48: 165173; doi.org/10.3233/WOR-131609.

[22] Al-Hadidi, F., Bsisu, I., AlRyalat, S. A., Al-Zu'bi, B., Bsisu, R., Hamdan, M., Kanaan, T., Yasin, M., \& Samarah, O. Association between mobile phone use and neck pain in university students: A crosssectional study using numeric rating scale for evaluation of neck pain. PloS one 2019; 14(5), e0217231; doi.org/10.1371/journal.pone.0217231.

[23] Yang, S.-Y., Chen, M.-D., Huang, Y.-C., Lin, C.-Y., \& Chang, J.-H. Association between Smartphone Use and Musculoskeletal Discomfort in Adolescent Students. J Community Health 2017; 42(3): 423-430.; doi: 10.1007/s10900-016-0271-x.

[24] Areeudomwong, P., Oapdunsalam, K., Havicha, Y., Tantai, S., \& Buttagat, V. Effects of Shoulder Taping on Discomfort and Electromyographic Responses of the Neck While Texting on a Touchscreen Smartphone. Saf Health Work 2018; 9(3): 319-325. ; doi.org/10.1016/j.shaw.2017.07.004 
[25] Pope-Ford R., 2020. Parent Awareness of Smartphone Use and Its Health Impact. In: Arezes P. (eds) Advances in Safety Management and Human Factors. AHFE 2019. Advances in Intelligent Systems and Computing, vol 969. Springer, Cham ;doi.org/10.1007/978-3-030-20497-6_20.

[26] Global Burden of Disease Study 2013 Collaborators, 2013. Global, regional, and national incidence, prevalence, and years lived with disability for 301 acute and chronic diseases and injuries in 188 countries, 1990-2013: a systematic analysis for the Global Burden of Disease Study 2013. Global Burden of Disease Study 2013. Lancet. 2015 Aug 22; 386(9995):743-800.; doi.org/10.1016/S01406736(15)60692-4.

[27] Gustafsson, E, Thomée, S, Grimby-Ekman A, Hagberg, M. Texting on mobile phones and musculoskeletal disorders in young adults: A five-year cohort study. Appl Ergon 2017; 58: 208-214; doi.org/10.1016/j.apergo.2016.06.012.

[28] Siivola SM, Levoska S, Latvala K, Hoskio E, Vanharanta H, Keinänen-Kiukaanniemi S.,2004. Predictive factors for neck and shoulder pain: a longitudinal study in young adults. Spine (Phila $\mathrm{Pa}$ 1976).29(15):166-29. 